\title{
OBSERVATIONS ON OCEAN TEMPERATURES IN THE VICINITY OF ICEBERGS AND IN OTHER PARTS OF THE OCEAN
}

\author{
By C. W. Waidner, H. C. Dickinson, and J. J. Crowe
}

Through the courtesy of the Navy Department an opportunity was afforded to the representatives of the Bureau of Standards to make observations on the temperature of sea water in the vicinity of icebergs and in the open sea with a view to obtaining information on the possibility of detecting the proximity of ice from temperature records. It is fairly evident from a long experience of navigating officers that the usual methods of taking the temperatures of sea water at widely separated intervals of time can give no useful information so far as detecting the proximity of icebergs is concerned. If any variations in the temperature are caused by the presence of ice, then continuous records of the temperature should be taken. The object of these experiments was to obtain such records and then to carefully analyze them with the view to ascertaining whether the proximity of icebergs gives rise to any definite temperature variations which can be distinguished from the accidental variations usually found in sea water.

The Bureau party embarked on the U. S. S. Chester, leaving Philadelphia on June 2, 1912, under command of Capt. Decker. Mr. Crowe subsequently transferred to the U. S. S. Birmingham, under command of Capt. Hughes, and continued observations from June ig until the return to the port of Philadelphia on July II, I 1912 . 


\section{TEMPERATURE EQUIPMENT}

The apparatus assembled for these experiments consisted of the following:

One electrical resistance thermometer with 50 -foot leads, and one with I 50 -foot leads, protected and insulated by 4-ply rubber hose, the longer hose being reinforced with wire rope (the thermometers were of the Callendar compensated type with four flexible copper leads and coil of silk-covered nickel wire of about Ioo ohms resistance); a surface electrical resistance thermometer, shown in Fig. I, consisting of a flat coil of silk-covered nickel wire inclosed between copper sheets and insulated by thin layers of mica (the resistance of the nickel coil was about roo ohms); deep-sea thermometers of the Negretti and Zambra type, kindly loaned by the Bureau of Fisheries; several standard mercurial thermometers; a Leeds \& Northrup recorder, Fig. 2, suitable for use with the resistance thermometers, and which was kindly loaned for these experiments by the Leeds \& Northrup Co; a Siemens \& Halske Wheatstone bridge; a Leeds \& Northrup Wheatstone bridge with Kohbrausch slide wire; a Leeds \& Northrup marine D'Arsonval galvanometer; a Siemens \& Halske high-resistance millivoltmeter; tools, wire, repair parts, etc.

All of the apparatus was carefully calibrated before leaving the laboratory.

The surface thermometer was mounted with its flat face directly against the inner surface of the ship's three-eighths-inch plates, about 6 feet below the water line. The location of the thermometer was in the torpedo room, forward, and on the starboard side. The thermometer was held into good contact with the plate by a suitable wooden strut which was thermally insulated from the thermometer by a layer of felt, and the whole protected by a thick layer of cotton to eliminate the effects of the temperature of the torpedo room. Special experiments showed that this thermometer responded quickly to changes of temperature of the surface with which it was in contact. Simultaneous measurements of temperature made with a sensitive mercurial thermometer in the injection water and with the surface thermometer and recorder, mounted as above, showed that the sudden changes in sea-water 



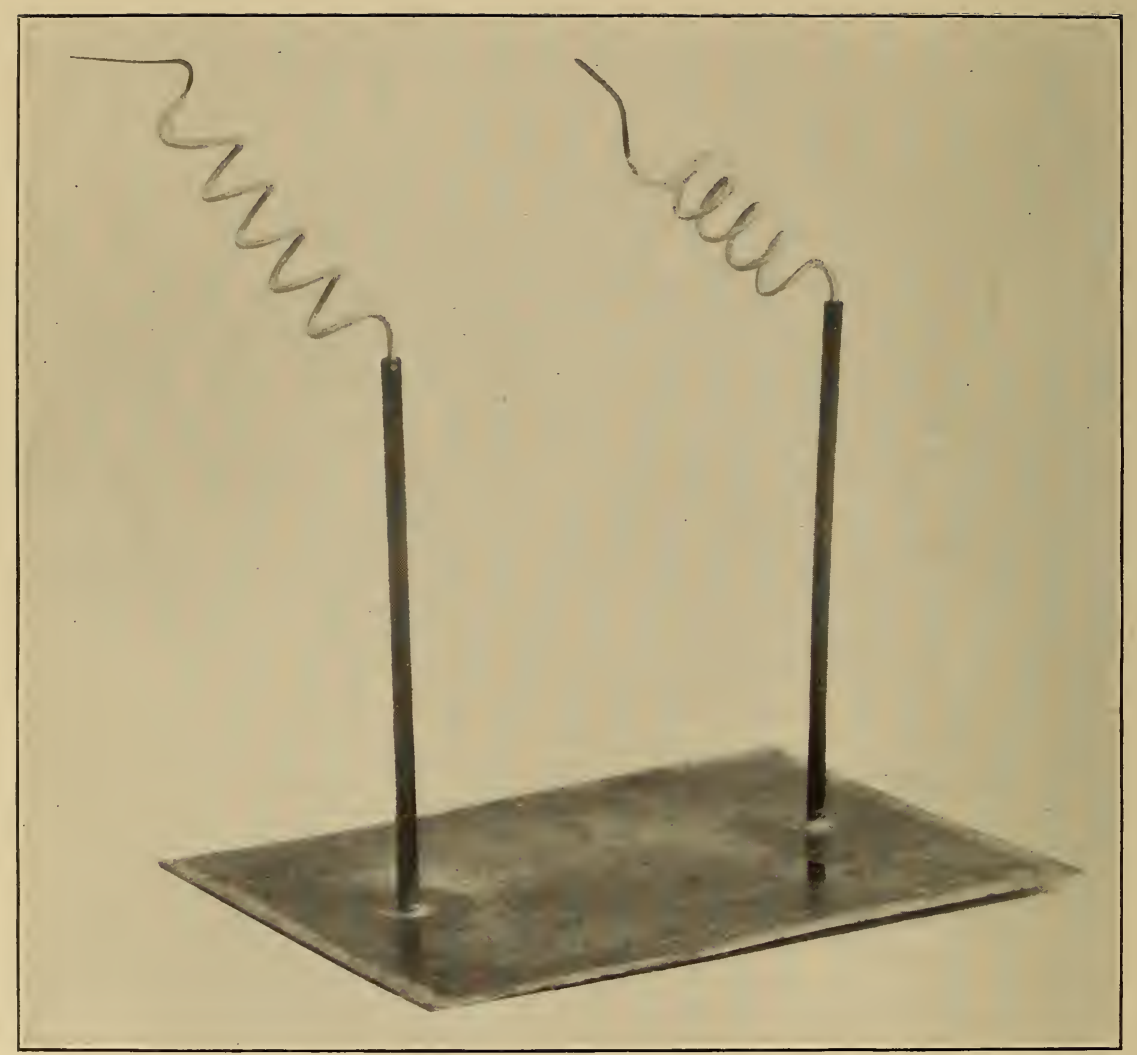

Fig. 1. -Surface electrical resistance thermometer 
temperature were indicated by the recorder without any significant time lag. As an additional check on the calibration of the surface thermometer it was compared frequently with standard mercurial thermometers.

The recorder was mounted on both ships in the torpedo room near the surface thermometer. The suspended system of the D'Arsonval galvanometer of this recorder was so carefully balanced by the makers that the records were entirely unaffected by the rolling and pitching of the ship, which was by no means inconsiderble, the rolling sometimes amounting to $20^{\circ}$ to $30^{\circ}$ on each side of the vertical. As used, a change of $\mathrm{I}^{\circ} \mathrm{C}$ corresponded to a movement of the pen of $18 \mathrm{~mm}$ on the record sheet. The displacement of the paper was about $60 \mathrm{~mm}$ per hour. Full details of the operation of this recorder have been published in the current engineering literature and may be had from the makers. This recorder, with the surface thermometer above described, gave such excellent satisfaction that it was not necessary to use any of the other apparatus which was taken on the trip for emergency use.

\section{TEMPERATURE RECORDS}

Practically continuous temperature records were obtained from June 4 until July ro, 1912. The temperatures recorded ranged from $3^{\circ}$ to $25^{\circ} \mathrm{C}$. The balance point of the recorder was changed to bring the temperature records on the paper by the insertion of suitable known resistances in one arm of the Wheatstone bridge circuit of the recorder, the calibration of the surface thermometer being made with the corresponding resistances in the circuit.

Sample records, together with a brief description of the conditions under which they were obtained, are given in Figs. 3-14.

Fig. 3 shows the temperature record obtained on board the U.S. S. Chester June I7, 1912. Several small bergs or growlers were sighted on the horizon at $9.45 \mathrm{a}$. m. Almost simultaneously the record shows a sudden fall of temperature from $8^{\circ} .7$ to $7^{\circ} \cdot 3 \mathrm{C}$, or nearly $\mathrm{I}^{\circ} .5 \mathrm{C}$. At this time the ship was over ro miles from the nearest of the growlers. The temperature continued to fall irregularly as the growler was approached until ro.45 a. m., when the temperature was $5^{\circ} .7 \mathrm{C}$, at which time the distance from the $2 ; 647^{\circ}-\mathrm{I}_{4}-8$ 
growler, estimated by the range finder, was about 500 yards. At I I a. $m$. the distance was about 150 yards. A party put out in a boat to take observations of temperature around the growler. In going around this growler, the mass of which was estimated at about 12000 tons, the surface temperature as determined by the observers in the lifeboat ranged from $5^{\circ} .8$ to $6^{\circ} .7 \mathrm{C}$.

At about r.20 p. m. the ship got under way, steaming toward a large berg about 12 miles distant. The course of the ship around this berg is shown by the diagram in the upper right corner of Fig. 3. The course D is about 6 or 7 miles in length. The various legs of this course $A, B,-G$ are also indicated on the temperature record, Fig. 3. No significance can be assigned to the irregular fluctuations of temperature observed around this berg. (See Fig. 15.)

About 5.25 p. m. the ship lay to abeam of the berg at a distance of 300 yards. A party put out in a small boat for temperature observations. The time until about $7 \mathrm{p}$. m. was spent in the immediate neighborhood of the berg, the ship sailing around the berg while the party in the small boat were taking observations. From about 7 to 9.30 p.m. the ship lay to; by this time the ship and berg had drifted apart. During the remaining time, until about midnight, the ship cruised around in an unsuccessful effort to locate the berg with the aid of two powerful searchlights.

From measurements made with two stadimeters, on the ship and on the whaleboat, respectively, the dimensions of the berg were determined. The mass of ice in this berg was thus estimated at about 400000 tons.

The mean of a number of temperature observations taken from the whaleboat gave the following surface temperatures: 20 feet from the berg, $4^{\circ} .5 ; 35$ feet, $4^{\circ} .9 ; 50$ feet, $5^{\circ} ; 75$ feet, $5^{\circ} .4 ; 200$ feet, $5^{\circ} .7 \mathrm{C}$. The temperature at a distance of 50 feet from the berg and at a depth of 5 fathoms was $3^{\circ} .6$, and at a depth of 20 fathoms $3^{\circ} \cdot 3$. At some miles distant from the berg temperatures were encountered as low as those observed a few feet from the berg.

Although the effort to locate the berg with the aid of searchlights was unsuccessful, at daybreak on the morning of the 18 th the berg was in plain view. Between 6 and $7 \mathrm{a} . \mathrm{m}$. the berg turned over in 


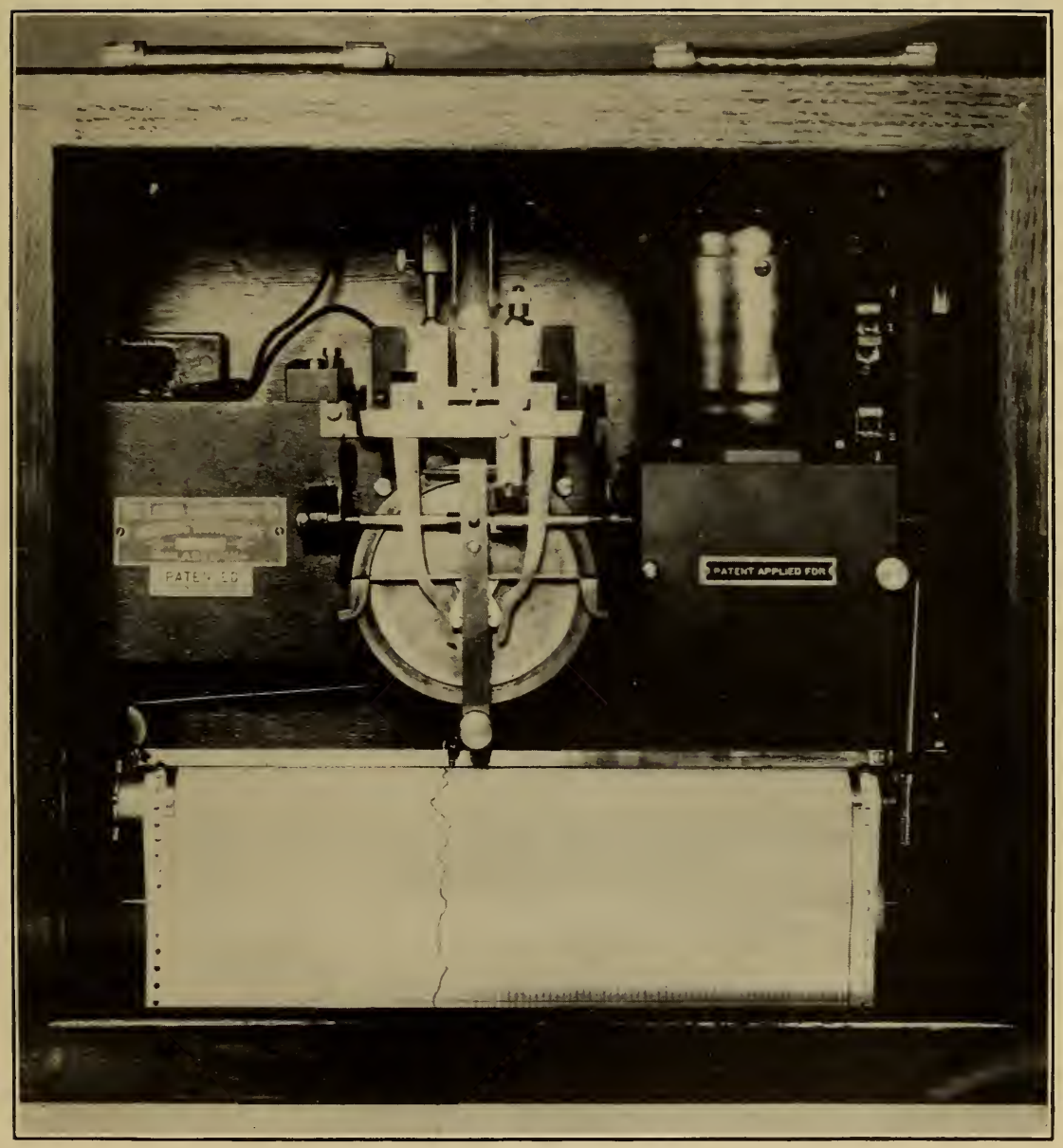

Fig. 2.-Leeds \& Northrup recorder 

an interval of about ro minutes, accompanied by several loud reports similar to the reports caused by firing 3 -inch guns.

On the morning of June 18 some time was spent in experiments to detect possible echoes, submarine and aerial, which are referred to elsewhere. At 9 a. $\mathrm{m}$. the ship got under way, starting from a point about 2 miles distant from the berg. The ship's course for the day is shown in Fig. 4. Attention is called to the remarkable similarity in the temperature records obtained in going away from and in returning to the morning position of the berg, although the courses traversed are not quite the same. On returning to the approximate position of the berg it was dark and foggy and it could not be again located, even with the aid of searchlights. From the temperature record it would appear that the ship was in the same water at $8 \mathrm{p.} \mathrm{m}$. as it had left at $9 \mathrm{a} . \mathrm{m}$.

Fig. 5 shows the temperature record corresponding to the following log: Ship approached berg steaming at ro knots, having left a large berg at $12.23 \mathrm{p}$. m., and was abeam, 200 yards distant, at 2 p. m. About 30 miles distant from this berg the ship passed a large growler, 200 yards distant; time, $5.20 \mathrm{p} . \mathrm{m}$.

The temperature record in approaching and leaving two bergs and a number of growlers and in steaming around one of the bergs is shown in Fig. 6.

Fig. 7 shows the temperature records obtained at night while steaming various courses around growlers in an attempt to locate the position of a large berg that was in plain view at daybreak the next morning. The portion of the curve after $4.30 \mathrm{p}$. m., when the ship was leaving the ice, is characteristic of temperature changes often observed in the open sea with no ice in sight.

Fig. 8 shows typical variations in sea-water temperatures, similar to those in the latter part of Fig. 5, with no ice in sight. The variations in the temperature here observed are as great and as sudden as any recorded in the neighborhood of bergs.

Fig. 9 shows the temperature record obtained when approaching the Grand Banks of Newfoundland. The drop in temperature here observed is similar to that observed by Barnes ${ }^{1}$ in approaching land or shallow water.

\footnotetext{
'Report on the Influence of Ice Bergs and Land on the Temperature of the Sea, etc., supplement to the Forty-fifth Annual Report of the Department of Marine and Fisheries, I911-12.
} 
Fig. Io shows the temperature records for the following log: 9.50 a. m., passed berg 400 yards abeam; II.35 a. m. to $\mathrm{I} 2$ noon, steamed around berg, when ship lay to with berg 75 yards abeam; I p. m., ship got under way, berg then I, I00 yards distant; I.55 p. m., ship headed for another berg sighted five minutes before; 4 p. m., ship lay to in dense fog; 4 to 6 p. m., when fog lifted, three new bergs were in view.

Fig. II is the temperature record obtained under conditions which are fully set forth in the figure.

Fig. 12 is the temperature record obtained in approaching, steaming around, and leaving a large berg.

Fig. I 3 shows the temperature record obtained on July 6 , on the return trip of the U. S. S. Birmingham in steaming west along latitude $42^{\circ} 23^{\prime}$ from longitude $48^{\circ} 54^{\prime}$ (at 8 a. m.) to $5 \mathrm{I}^{\circ} 28^{\prime}$ (at 8 p. m.). This curve shows typical variations in ocean temperatures. The variations are large and sudden, although no ice is near.

Fig. 14 is the temperature record in steaming along course latitude $4 \mathrm{I}^{\circ} 5 \mathrm{I}^{\prime}$, longitude $60^{\circ} \mathrm{I} 4^{\prime}$ (at 8 a. m.), to latitude $4 \mathrm{I}^{\circ} 26^{\prime}$, longitude $63^{\circ} \mathrm{o} 7^{\prime}$ (at 8 p. m.).

\section{VARIATIONS IN THE SALINITY OF SEA WATER}

Variation in the salinity of sea water in the neighborhood of icebergs due to the diluting action of the water resulting from the melting of the ice is so small as to be entirely masked by the accidental variations found in sea water. The following determinations of the densities of samples of sea water, taken under conditions specified and which were afterwards tested in the laboratories, will serve to illustrate this:

\begin{tabular}{l|l|l|}
\hline Sample & $\begin{array}{c}\text { Specific gravity } \\
\text { at } \frac{20^{\circ}}{4^{\circ}} \mathrm{C}\end{array}$ & Remarks \\
\hline 1 & 1.02339. & Close to berg \\
2 & 1.02352 & Close to another berg \\
3 & 1.02340 & 400 yards from berg \\
4 & 1.02336 & 40 miles from berg \\
5 & 1.02319 & 60 miles from berg \\
6 & 0.99923 & Water from berg ice \\
7 & 0.99923 & Distlled water \\
\hline
\end{tabular}




\section{ECHOES FROM ICEBERGS}

The testimony of numerous observers is in evidence that the echo of the foghorn may frequently, but by no means always, be detected when in the proximity of an iceberg or even of a bank of fog. The amount of evidence on this point leaves no doubt as to the correctness of the above statement. The experiment of sounding the foghorn when in the vicinity of a number of the bergs encountered on the trip was tried, but in no instance was an echo detected.

A few experiments were also made to determine whether an echo could be detected under water coming from the larger submerged portion of the berg. For this purpose the ship's bell was lowered into the water and signals produced by striking the bell. Observers stationed at the ship's submarine signal telephones listened for evidences of the echo. The ship was at a distance of I to 2 miles from the fair-sized berg encountered by the U. S. S. Chester on the afternoon of June I7. It was difficult to draw positive conclusions on account of the disturbing noises present in the telephone receiver, but a number of observers were convinced that they heard faint echoes. There was no time to investigate and improve the telephonic apparatus, so that the most that can be said is that these preliminary experiments looked hopeful enough to merit more careful experiments along these lines.

\section{OTHER OBSERVATIONS}

The results of other experiments, such as firing 3 and 5 inch shells into the berg, the utility of searchlights in locating bergs at night, etc., will undoubtedly be covered in the official reports of the commanding officers. It may be worth while to record, in passing, for the information of the reader, the general impressions of the authors, unfamiliar with such matters, that the effects of cannon fire in breaking up icebergs were disappointingly small and the utility of powerful searchlights in their location surprisingly limited.

Although the lookouts were provided with spyglasses or with binoculars, it is of interest to note that the icebergs were invariably first seen with the unaided eye. The difficulty of picking 
up icebergs under some conditions is illustrated by the following incident: While the ship was steaming toward a large berg in sight a heavy fog fell. There was one lookout in the crow's nest, four on the bridge, and two in the ship's eyes. Notwithstanding this the berg was first picked up from the quarterdeck after the ship had passed some 200 yards abeam.

Samples of ice broken from the berg by gun fire were taken aboard ship. These contained considerable amounts of included air, which probably accounts for their white appearance. The ice was surprisingly hard and free from any definite cleavage planes. The whitish appearance was generally characteristic of all the bergs met with. In some instances there were narrow streaks of ice, transparent and of a blue color, that penetrated entirely through the bergs.

The water resulting from the melting of the berg ice was found to have the same density as that of distilled water. (See p. 8.) It was free from any characteristic taste.

So far as our observations go, the temperature of the air furnishes no evidence of value as to the proximity of a berg.

\section{DISCUSSION OF OBSERVATIONS}

An examination of the temperature records herewith submitted, which were obtained under a variety of conditions in the region $37^{\circ}$ to $43^{\circ} 30^{\prime}$ north latitude and $43^{\circ}$ to $53^{\circ}$ west longitude, at once impresses one with the difficulty of separating the large and sudden variations of sea-water temperature, so frequently met with, from any variations that may be caused by the proximity of icebergs. The authors have obtained records in some parts of the ocean in which the temperatures were practically constant to a few tenths of a degree for many hours. On the other hand, some of the sample records submitted show that the temperature variations in other parts of the ocean, where no ice is near, are as great and as sudden as any observed in the neighborhood of bergs. Having established the existence of such variations in sea-water temperatures, it follows that it will be very difficult and often impossible to draw definite conclusions as to the proximity of ice from temperature records. 
In approaching or leaving a berg the temperature of the sea water may rise or fall or remain practically constant. Thus in Fig. 3 , in approaching the large berg along course $\mathrm{D}$, the temperature varied irregularly through a range of about $0.2^{\circ} \mathrm{C}$, a variation much less than is frequently observed in this distance. Along some of the courses the temperature fell in approaching the berg (e. g., course A), and along course $\mathrm{G}$, for example, the temperature varied quite irregularly. In Fig. I 5 the temperature records of Fig. 3 are reproduced, the temperature at the iceberg being arbitrarily taken as the zero of temperatures for each course. Curve a, Fig. I 5, is the temperature record in approaching and leaving a growler. The remainder of the curves in this figure (I5) are the records for all the courses around the large berg, shown in Fig. 3 . The temperature records for the different courses differ so much that no certain effect can be attributed to the iceberg. The mean of the curves for all the courses is shown in the lower part of Fig. 15 .

In Fig. I 6 are reproduced all the temperature records given, except those of June 17 , for approaching and leaving icebergs, the temperatures at the bergs being always arbitrarily taken as the zero of temperature. The mean curve shown below indicates that in general there was a fall in temperature of about ${ }^{\circ}$ in 4 or 5 miles in approaching the various bergs. In all but two instances the minimum temperature was found near the bergs.

The temperature records published by Prof. Barnes very generally show a rise in temperature as a berg is approached, occasionally accompanied by a slight fall in temperature very near the berg. Prof. Barnes regards the rise of temperature as the "characteristic iceberg effect" and attributes any drop in temperature to cold currents. His records show the normal variations of seawater temperature in the localities of his observations to be very much smaller than were observed in the parts of the ocean where our observations were made. Although many of the small temperature variations which appear significant in his records would be completely masked by the large and sudden temperature changes which our records show, nevertheless the magnitude of the sc -called "iceberg effect" observed by Prof. Barnes being often $05^{\circ}$ to $2^{\circ} \mathrm{C}$, such changes would be very evident on our records 
where changes of a few hundredths of a degree are readily discernible.

Our records do not corroborate Barnes's characteristic iceberg effect. Twelve of the 14 curves, as well as the mean curve, of Fig. I 6 certainly show no such rise in temperature. Most of these curves indicate the opposite effect.

As Prof. Barnes's and our own records are matters of observation which unquestionably represent conditions that were actually encountered, it would seem that the effects due to bergs, if such effects can yet be regarded as established, must be different under different conditions. Indeed, that such is the case is shown by the different temperature records obtained in approaching a given berg along different courses.

Enough data is not yet at hand to formulate a theory to account for the variations of temperature observed in the vicinity of icebergs. Indeed, the question is still in doubt as to whether they influence to any measurable extent the temperatures of sea water at any considerable distance (a mile or so).

In view of the observations of Barnes and of the authors on the salinity of surface water at different distances from bergs, it seems fairly certain that the layer of cold fresh water resulting from the melting of the berg, and which was supposed on Pettersson's theory to spread out over the surface in the vicinity of an iceberg, causes no measurable dilution or change of salinity of the surface layer.

Barnes's records so uniformly show a rise of temperature as the berg is approached that he has termed this observed rise "the iceberg effect." This effect is not characteristic of our records. Indeed, on the average, the authors observed a fall in temperature from a distance of several miles up to the bergs. In view of the erratic variations of the temperature of these parts of the ocean when no ice is near and of the fact that in approaching a given berg along different courses the temperature variations are quite different (being nearly constant over some courses and falling very appreciably over other courses), we would not deem it justifiable to conclude that the observed variations were certainly connected with the presence of the bergs.

It is interesting to inquire a little further into the question whether any cooling action of the berg could be expected to make 
Waidmer,

itself felt at any considerable distance from the berg. If the berg is constantly drifting into new waters, such effect would obviously be impossible from the consideration of the fact that it would require the melting of about a million tons of ice to cool I square mile of the ocean to a depth of only 25 feet by ${ }^{\circ} \mathrm{C}$.; hence the possibility of any significant cooling action would require that the berg and the water in which it is immersed drift together for a considerable period of time, i. e., that the relative motion be small. This is probably true under some conditions, but by no means always. Considerations, such as these, of the enormous mass of ice required to produce a cooling action distinguishable from temperature variations due to other causes, the slowness of melting of the berg, etc., render it doubtful whether any, such effect could be distinguished with certainty at distances of a mile or so. To account for the observed rise in temperature or "iceberg effect" Barnes has advanced an ingenious theory. He assumes that in regions of the ocean at some distance from the berg the surface layer, heated by solar radiation, is mixed with the colder water below by the "normal vertical circulation," while near the berg there is a current set up toward the berg due to the combined effects of the melting and cooling action of the berg. This current toward the berg, it is assumed, interferes with the "normal vertical circulation" so that the warm water remains on the surface. It is difficult to understand how a sufficiently strong current toward the berg could be set up by the melting and cooling action of the berg to interfere with the "normal vertical circulation " at a distance of a mile or two. That there is no very strong current toward the berg seems to be indicated by the drifting apart of the fragments of a berg from the berg itself or of the larger parts of a berg after breaking up. Difference of wind action may, however, complicate any conclusions based on such observations.

\section{CONCLUSIONS}

The records of sea-water temperatures obtained by means of an electrical resistance thermometer and a Leeds \& Northrup temperature recorder, installed on the U. S. S. Chester and Birmingham in their patrol of the North Atlantic Ocean in June and 
July, I912, show that the temperature variations in parts of the ocean far removed from ice are often as great and sudden as in the neighborhood of icebergs.

For a majority of the courses of the ship in the vicinity of icebergs there was a fall in temperature from a fraction of a degree to $3^{\circ}$ in a distance of 4 or 5 miles on approaching the berg. Records were obtained, however, in which the character of the temperature variation varied with the direction of approach to the berg, the temperature being nearly constant over one course, while over other courses the temperature rose or fell as the berg was approached. So far as our records go, therefore, it does not seem possible to draw positive conclusions as to the absence or proximity of ice from the temperature records of sea water. This is not a condemnation of the use of suitable recorders on ships. As Barnes has shown, the temperature record may give valuable information on the approach to shore and shallow water, on the identification of characteristic ocean currents, and, as his records seem to show, even of the proximity of icebergs in some parts of the ocean where the variations are less erratic than in the regions in which our observations were made.

If the "characteristic iceberg effect" observed by Barnes, i. e., rise of temperature on approaching icebergs, had been present around the bergs observed by us and of the same or even much less magnitude, our records would have rendered such an effect evident, notwithstanding the irregular variations of temperature usually found to exist. In view of the differences in the character of the records obtained by Barnes and ourselves, it is very desirable that further observations be made in different parts of the ocean, and under as varied conditions as possible, before attempting to draw final conclusions.

In conclusion the authors wish to express their deep sense of obligation to Capt. Decker and Capt. Hughes and to their officers and crews for hearty cooperation and many acts of kindness during their stay on shipboard.

WaSHINGTON, August I, I9I3. 


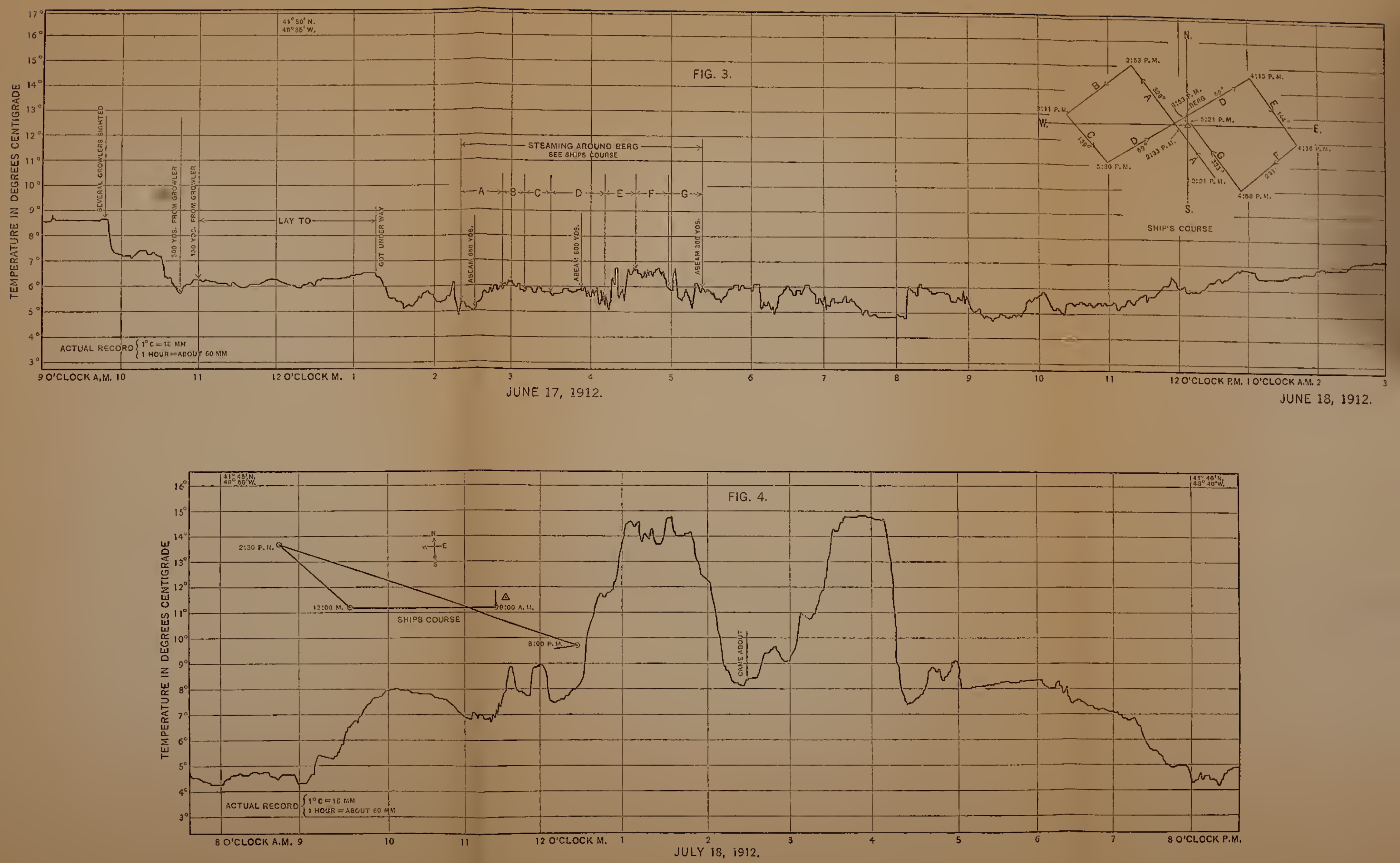



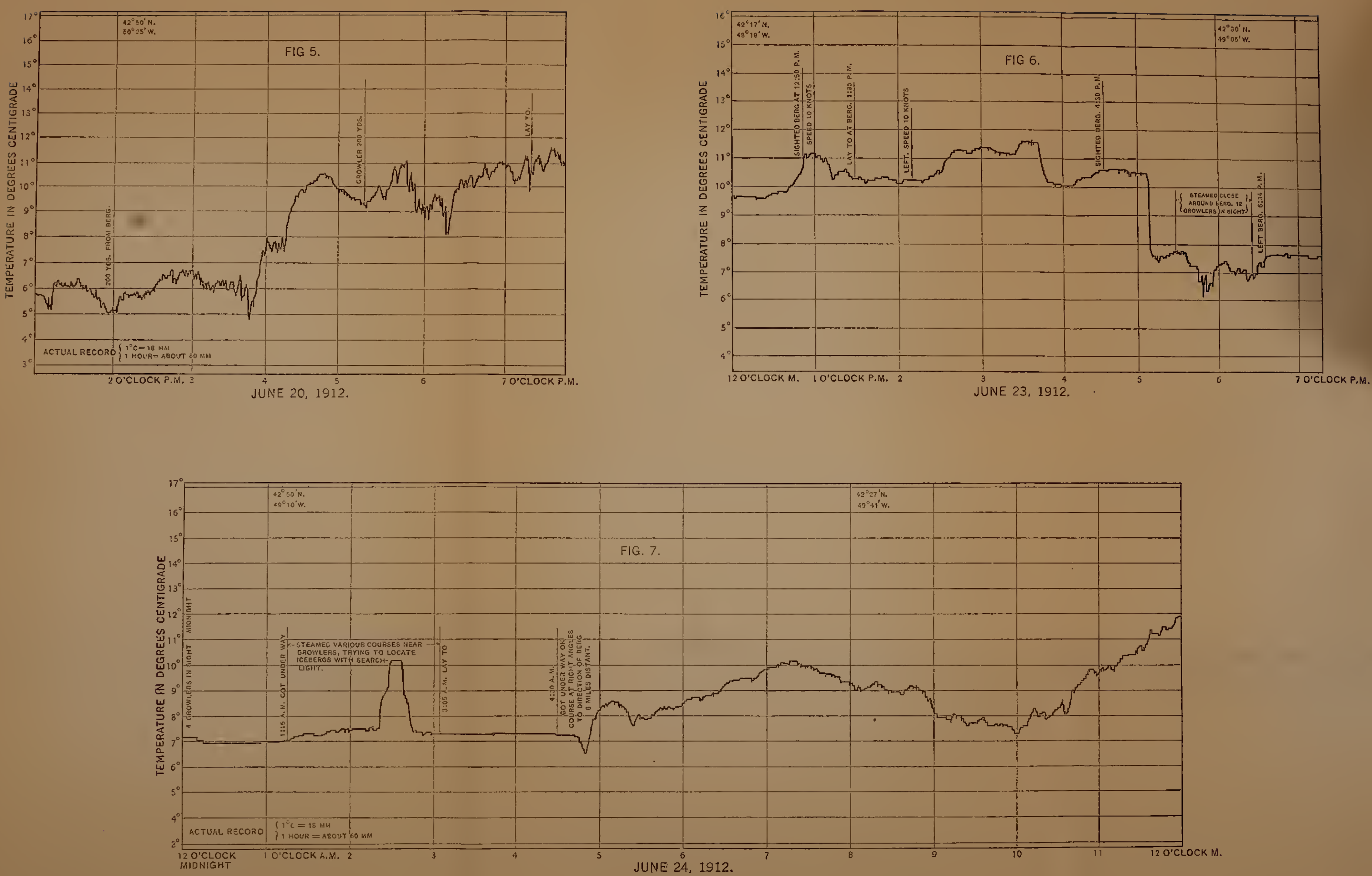


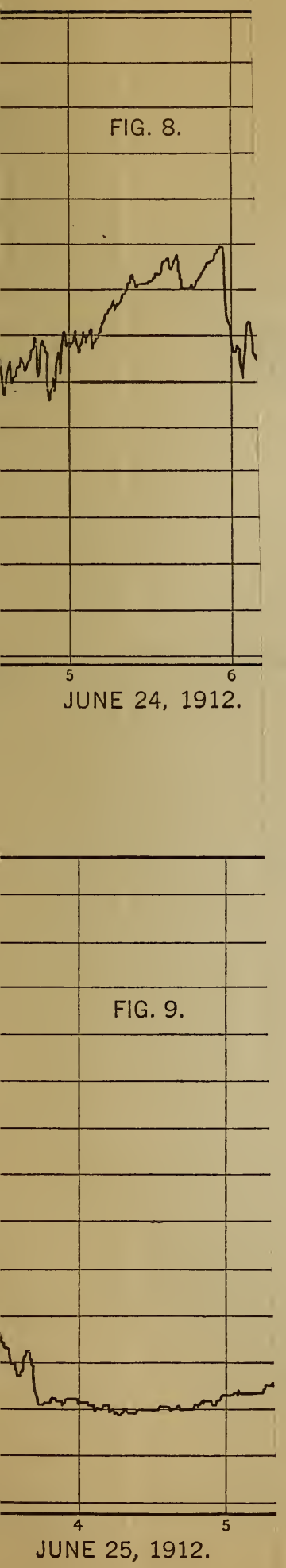


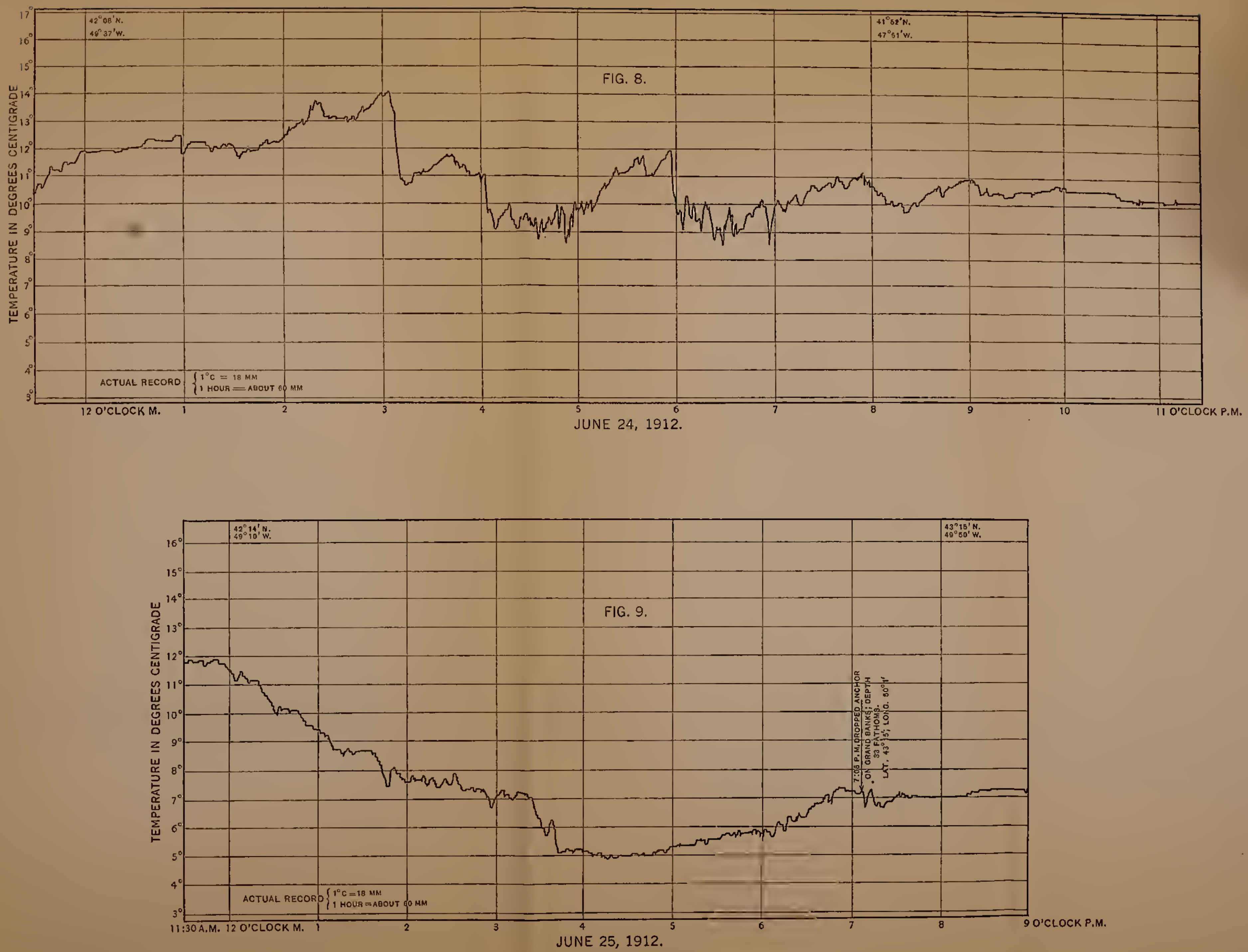


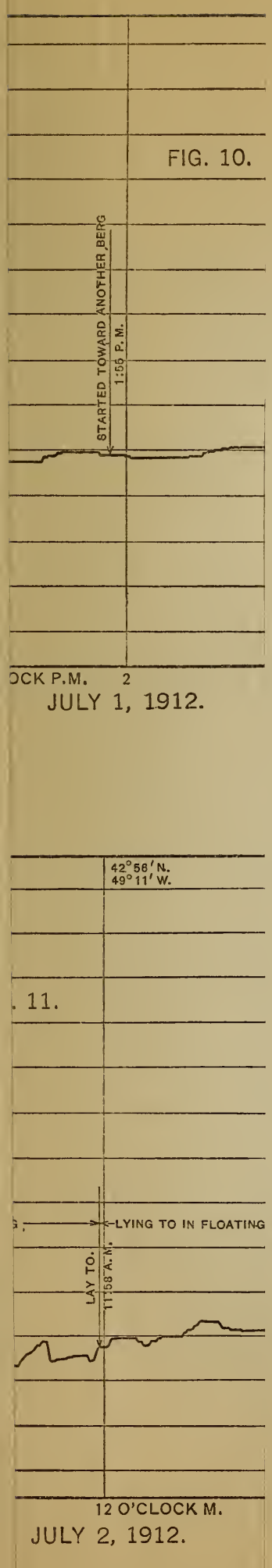


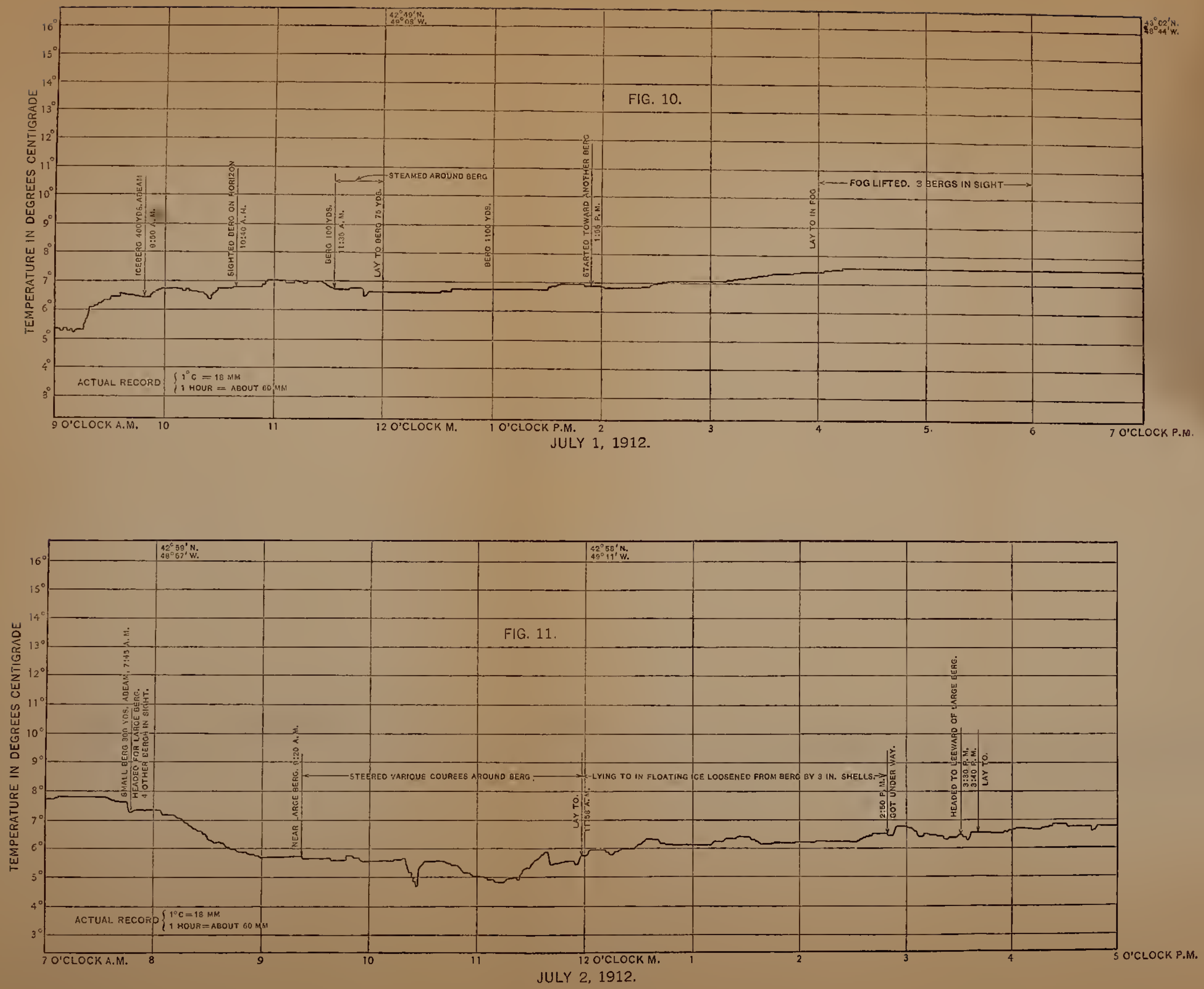



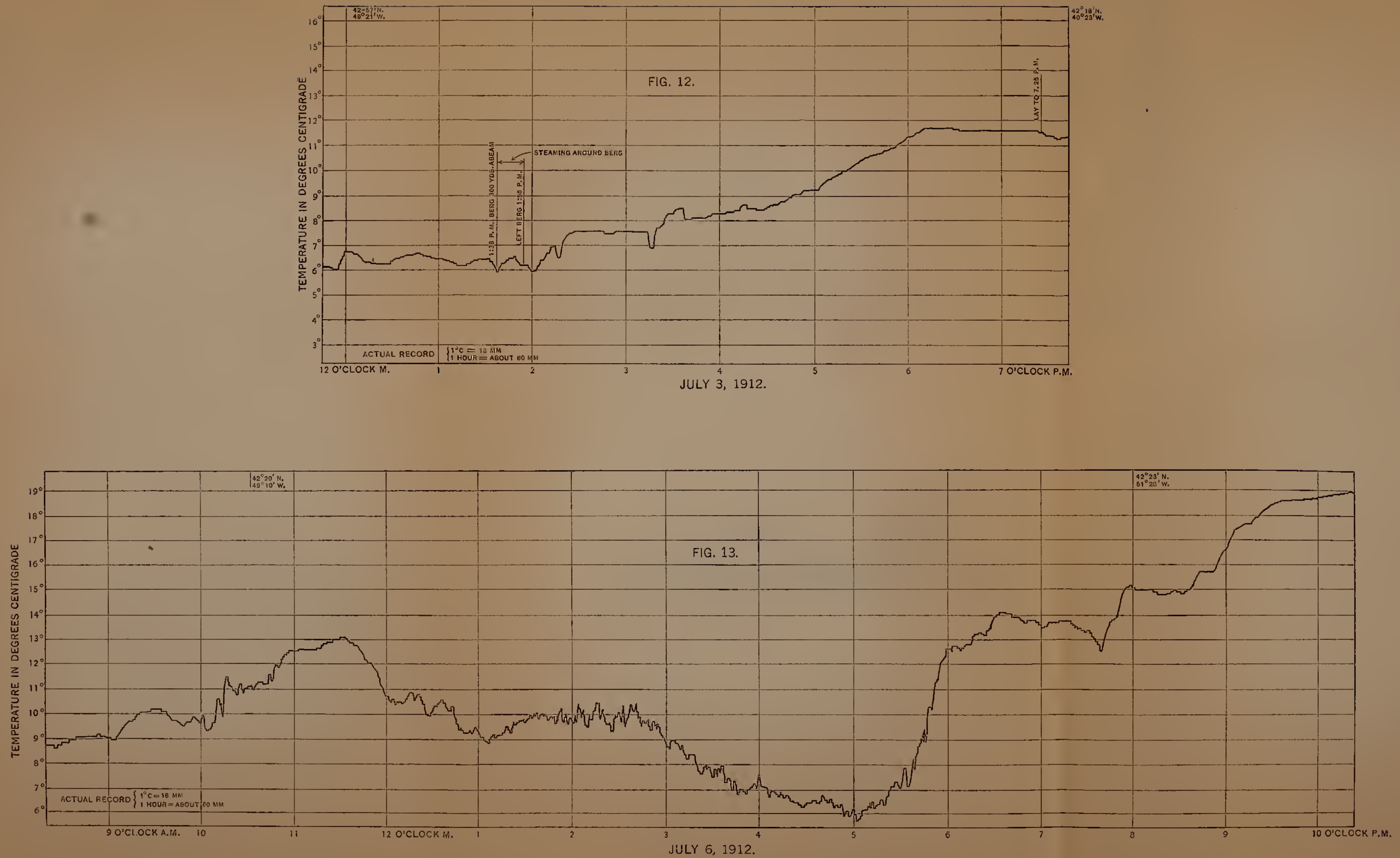



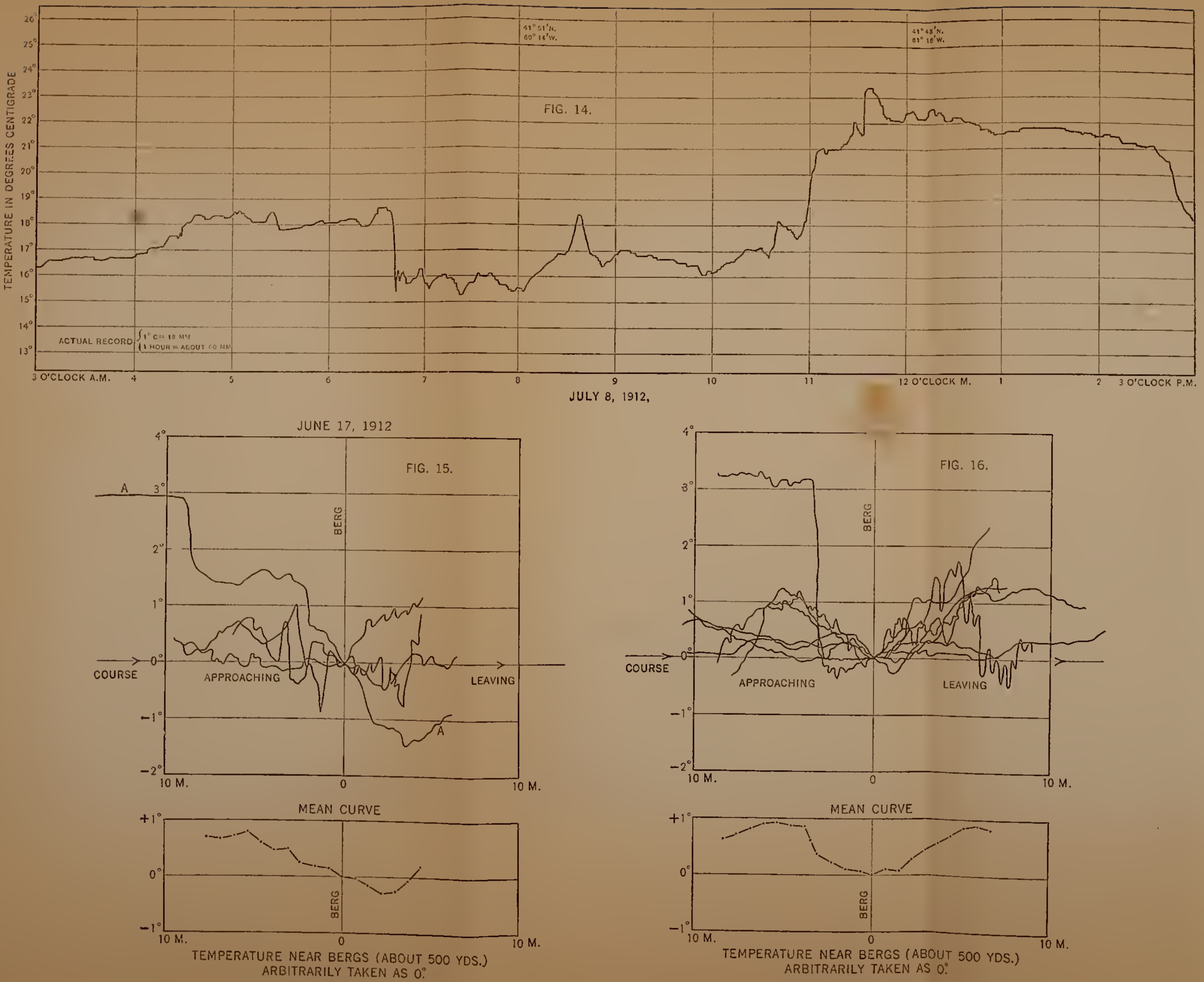



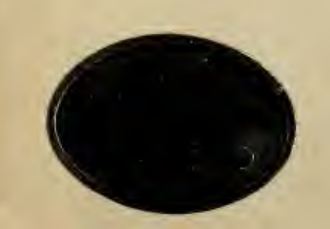


